\title{
Spotlight on measles 2010: Ongoing measles outbreak in Greece, January-July 2010
}

D Pervanidou (pervanidou@gmail.com) ${ }^{1}$, E Horefti², S Patrinos ${ }^{1}$, T Lytras $^{1}$, E Triantafillou ${ }^{1}$, A Mentis $^{2}$, S Bonovas $^{1}$, T Panagiotopoulos ${ }^{1,3}$

1. Department of Surveillance and Intervention, Hellenic Centre for Disease Control and Prevention, Athens, Greece

2. National Measles Reference Laboratory, Hellenic Pasteur Institute, Athens, Greece

3. Department of Child Health, National School of Public Health, Athens, Greece

Citation style for this article:

Pervanidou D, Horefti E, Patrinos S, Lytras T, Triantafillou E, Mentis A, Bonovas S, Panagiotopoulos T. Spotlight on measles 2010: Ongoing measles outbreak in Greece, January-July 2010. Euro Surveill. 2010;15(30):pii=19629. Available online: http://www.eurosurveillance.org/ViewArticle.aspx?Articleld=19629

Article published on 29 July 2010

A measles outbreak (126 reported cases to date) has been ongoing in Greece, since January 2010, originally related to the recent outbreak in Bulgaria. Cases are mostly unvaccinated, and mainly belong to three groups: Roma population of Bulgarian nationality, Greek Roma population, and Greek non-minority population. In these population groups, $67 \%$, $95 \%$, and $25 \%$ of cases respectively were children aged 0-14 years. Measures were taken to raise clinical awareness, and vaccination of specific population groups was undertaken. Policies are necessary to increase routine vaccination uptake of hard-to-reach groups.

\section{Background}

Measles is still present in Europe, causing severe complications and deaths in children $[1,2]$. Despite a large decline in measles incidence in the past decade in Europe, the World Health Organization (WHO) target to eliminate measles in Europe by 2010 does not seem feasible [2]. A measles outbreak with more than 20,000 reported cases has been taking place in Bulgaria since April 2009 [3,4], and clusters of cases have been reported from several countries in Europe in 2009 and 2010 [5-9].

Measles is a notifiable disease in Greece; the European Union (EU) case definition of 2008 is used [10]. Overall, measles incidence has been steadily declining in Greece during the past 25 years. The last measles outbreaks occurred in Greece in 1996 and in 2005 and 2006 (Figure 1).

The 2-5-year measles epidemic cycles previously observed ended after the 1996 measles outbreak. The last outbreak, in 2005-2006, had mainly affected unvaccinated Roma children aged 0-14 years, older

\section{FIGURE 1}

Reported measles cases by year of notification, Greece, 1 January 1990-25 July 2010

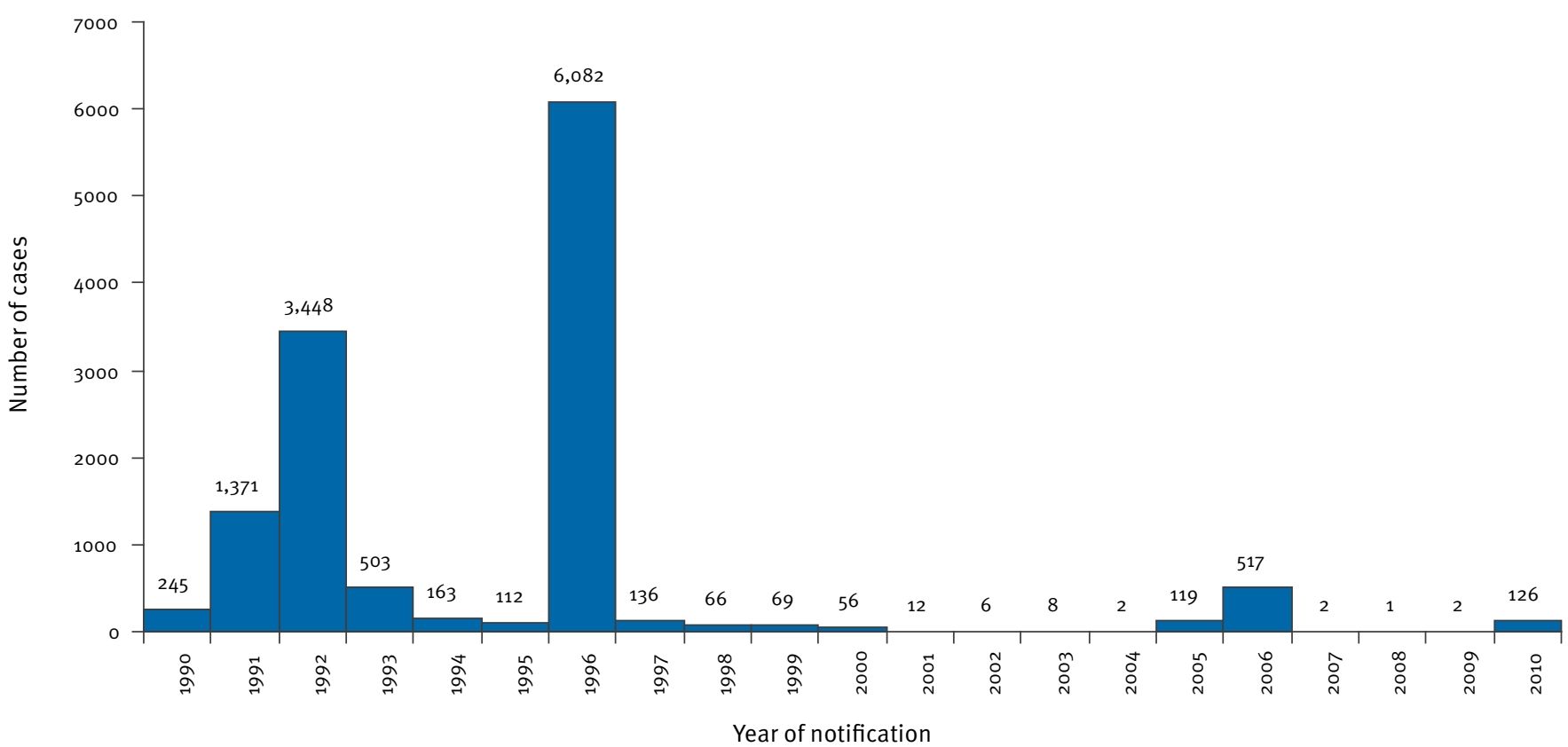


teenagers and young adults from the non-minority general population who were either unvaccinated or had had one dose of measles-containing vaccine, and unvaccinated or incompletely vaccinated immigrants [11].

\section{Ongoing measles outbreak in Greece}

A total of 126 measles cases have been reported to the Hellenic Centre for Disease Control and Prevention through the mandatory notification system by 25 July 2010 (rate 1.1 cases per 100,000 population). The first case was notified on 29 January 2010.

\section{Case classification}

Seventy-seven (61\%) of 126 reported cases were laboratory-confirmed (by serology and/or by PCR). Thirtyone cases $(25 \%)$ were classified as probable (cases meeting the clinical criteria with an epidemiological link). Eighteen cases (14\%) were classified as possible (cases meeting the clinical criteria).

\section{Laboratory investigation}

So far, measles virus genotype D4 was identified in all 19 cases genotyped by the National Measles Reference Laboratory (Hellenic Pasteur Institute). Nine of these cases are of Bulgarian nationality (Roma), nine are of Greek nationality (six of them are Roma) and one case is of Albanian nationality. Genotyping is in process for more cases.

\section{Nationality / high-risk populations}

Thirty-six (29\%) of 126 reported cases belonged to Roma communities of Bulgarian nationality, mostly families of seasonal workers in Greece (usually living in poor conditions). Eighty-seven cases (69\%) were persons of
Greek nationality, 43 (34\%) of whom belonged to the Greek Roma community. Seven cases $(6 \%)$ were healthcare workers. Three $(2 \%)$ cases were persons of other nationalities (one immigrant from Albania, one tourist from Denmark and one from France).

\section{Progress of the outbreak over time}

As indicated in the epidemic curve (Figure 2), during the first seven weeks of the outbreak, the majority of cases were of Bulgarian nationality. In the following weeks cases of Greek nationality were reported as well, and after week 21/2010 the majority of cases belonged to Greek Roma communities.

\section{Age distribution}

Seventy-eight $(62 \%)$ of 126 reported cases were children aged 0-14 years, with the largest number of cases $(n=34,27 \%)$ in the age group of $1-4$ years. Ten cases $(8 \%)$ were younger than 1 year.

As indicated in the Table, the majority of measles cases of Bulgarian nationality were children 0-14 years $(67 \%)$, mainly children aged $0-4$ years ( $42 \%)$. Almost all cases in the Greek Roma population were children aged 0-14 years (95\%), half of whom were $0-4$ years-old. The majority of cases from the non-minority Greek population were young adults older than 20 years $(66 \%)$.

\section{Vaccination status}

Information on vaccination status was reported by physicians who got this information from children's health booklets, or by parents or patients themselves. Of the 106 measles cases with known vaccination status, 93 cases $(88 \%)$ were reported as unvaccinated. Thirteen cases $(12 \%)$ were vaccinated for measles, all of them

\section{FIGURE 2}

Reported measles cases by week of symptoms' onset and by population group, Greece, 1 January-25 July 2010 (n=122

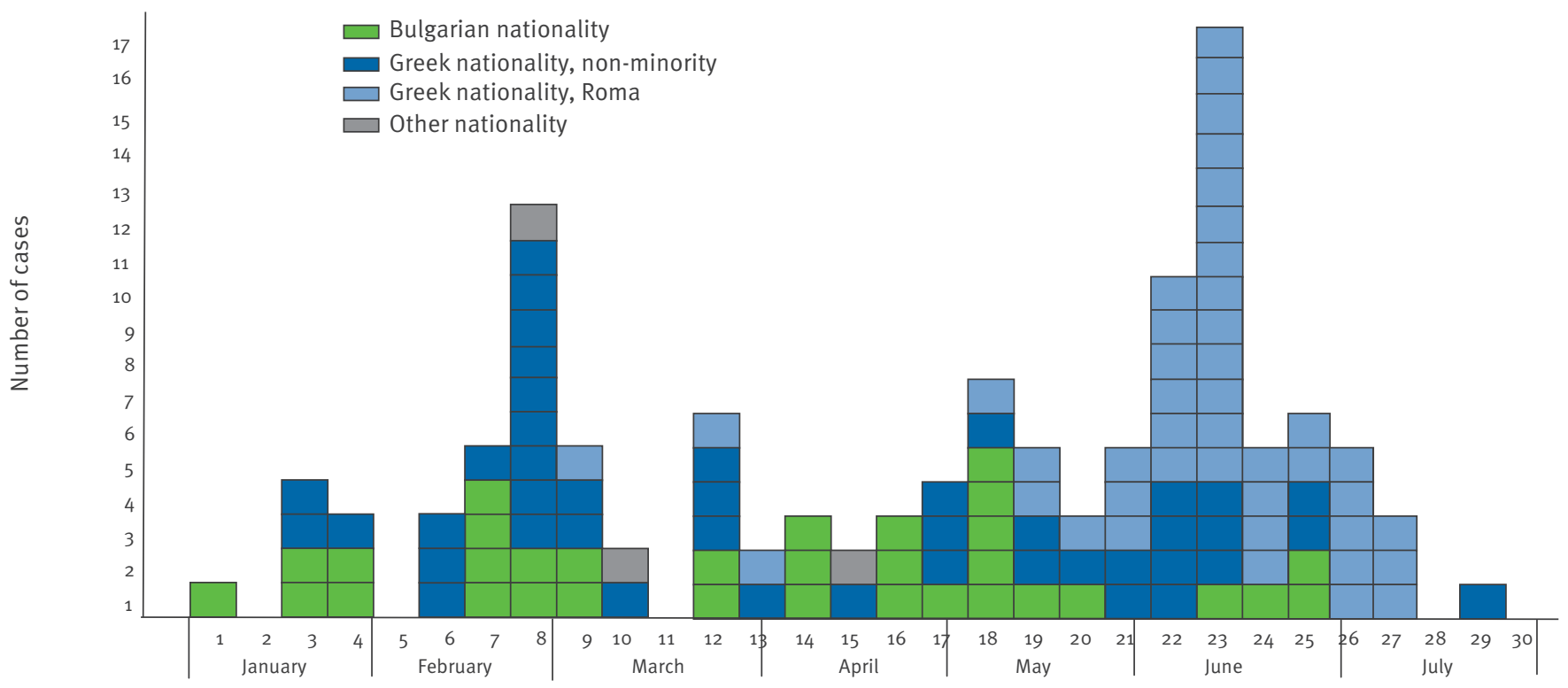

Week of onset 2010 
of Greek nationality (12 cases from the non-minority general population and one from the Roma community). Nine cases were reported to have had one dose of measles vaccine (the case from the Roma community was vaccinated seven days before disease onset) and four cases were vaccinated with an unspecified number of doses.

\section{History of recent travel abroad}

Information on recent travel abroad (within three weeks before onset of symptoms) was available for 114 of the 126 cases. One hundred and four cases ( $91 \%)$ had no history of recent travel abroad, including 22 cases of Bulgarian nationality. Ten cases (9\%) had a history of recent travel: eight cases had recently travelled to Bulgaria (six persons of Bulgarian nationality, one Roma person of Greek nationality and one of Danish nationality), one case to France (person of French nationality) and another one had an unknown travel itinerary.

\section{Hospitalisation, complications and outcome} Of the 125 cases with known hospitalisation status, $83(66 \%)$ were hospitalised. Of 125 measles cases with known complication status, complications were reported in $31(25 \%)$ of the cases. Complications included pneumonia (18 cases), otitis media (seven cases), laryngitis and/or bronchitis (six cases). Measles was complicated by meningitis in one male aged 29 years, whose vaccination status was unknown. No death has been reported.

\section{Geographical distribution}

The first measles clusters were reported from the district of Ilia in southwestern Greece (a total of 30 cases, most of them in three villages) and from the island of Crete (six cases from the district of Chania and 13 cases from the district of Heraklion, 10 of them from one village). No connection was identified between the clusters in Ilia, Chania and Heraklion.

As of 25 July 2010 measles cases have been reported from 21 of the 52 districts of the country, without any apparent geographical pattern. Clusters have been reported in Greek Roma camps (33 cases from eight clusters in Greek Roma camps) and in villages where Roma of Bulgarian nationality stay ( 26 cases from five villages). The largest reported cluster had thirteen cases (12 cases from one village, most of them relatives, and one healthcare worker) all belonging to the Greek non-minority population. Only two of the clusters were directly related to imported cases with recent travel history abroad. Of infants under 1 year, half (5/10) were part of family clusters, and one was part of a community cluster.

\section{FIGURE 3}

Notified measles cases and incidence rate per 100,000 population in the 13 administrative regions, Greece, 1 January-25 July 2010

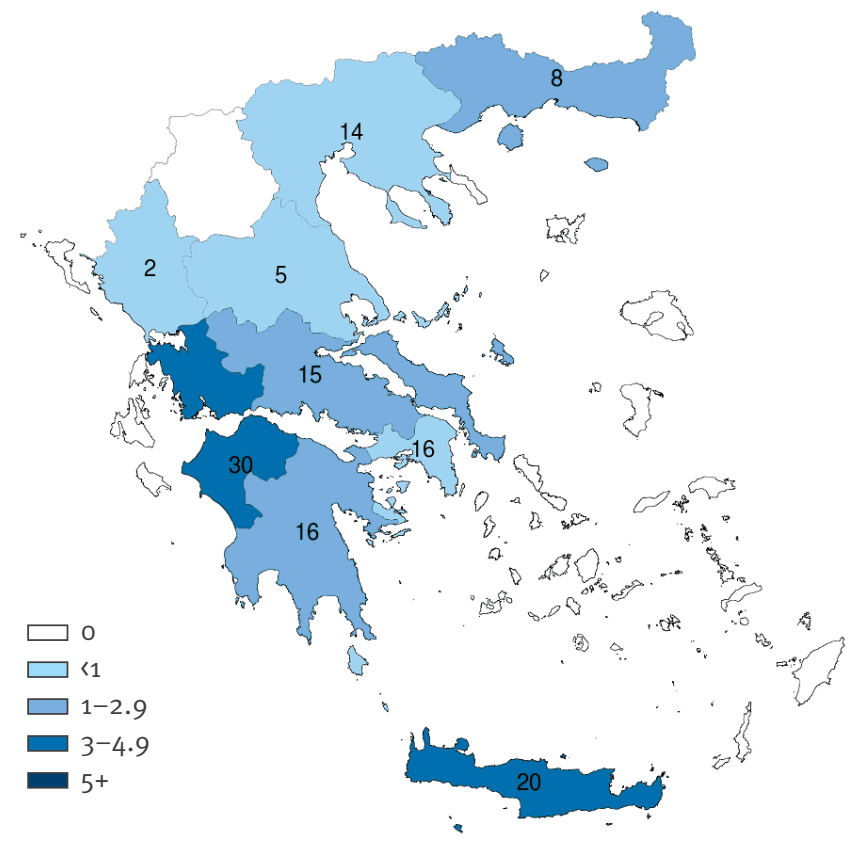

Numbers in the regions represent cases.

Numbers and colours in the legend represent incidence per 100,000 population.

TABLE

Reported measles cases by age group and nationality/population group, Greece, 1 January-25 July 2010 (N=126)

\begin{tabular}{|c|c|c|c|c|c|}
\hline Age group (years) & $\begin{array}{l}\text { Bulgarian nationality, } \\
\text { Roma }\end{array}$ & $\begin{array}{c}\text { Greek nationality, } \\
\text { non-minority }\end{array}$ & $\begin{array}{c}\text { Greek nationality, } \\
\text { Roma }\end{array}$ & Other nationality & Total \\
\hline$\ll 1$ & 4 & 1 & 5 & 0 & 10 \\
\hline $1-4$ & 11 & 5 & 16 & 2 & 34 \\
\hline $5-9$ & 4 & 3 & 9 & 0 & 16 \\
\hline $10-14$ & 5 & 2 & 11 & 0 & 18 \\
\hline $15-19$ & 3 & 4 & 0 & 0 & 7 \\
\hline $20-24$ & 3 & 8 & 1 & 0 & 12 \\
\hline $25-29$ & 2 & 7 & 1 & 0 & 10 \\
\hline$\geq 30$ & 4 & 14 & 0 & 1 & 19 \\
\hline Total & 36 & 44 & 43 & 3 & 126 \\
\hline
\end{tabular}




\section{Control measures}

The following public health measures were implemented. All regional and local public health authorities, physicians and other healthcare workers in the public and private sector in Greece were informed about this outbreak and the outbreak in Bulgaria, and about the appropriate investigation and management of measles cases and their contacts (isolation of cases, contact tracing and vaccination of susceptible contacts). Guidelines for measles control were distributed to healthcare staff and are available on the website of the Hellenic Centre for Disease Control and Prevention (www.keelpno.gr). Furthermore, physicians were alerted to increase their awareness for measles cases and to strengthen surveillance and to complete routine immunisation of children, adolescents and young adults in the wider community, according to the national immunisation schedule. In addition, vaccination campaigns of population groups with low vaccine coverage were organised in the country, with priority to high risk communities (mainly Roma) in affected areas.

\section{Discussion and conclusions}

This is a preliminary report of an ongoing measles outbreak in Greece, based on national surveillance data. The first cases and clusters were among persons of Bulgarian nationality, probably related to the measles outbreak in Bulgaria which started in April 2009 [3]. However, the high proportion of Greek nationals, mainly from Roma communities, underlines that despite the high national immunisation coverage with measles-mumps-rubella (MMR) vaccine, pockets of unvaccinated populations still exist.

Vaccination with two doses of MMR vaccine has been included in the national immunisation schedule in Greece since 1991. According to the national immunisation schedule, vaccination with the first dose of MMR is recommended at the age of 12-15 months and with the second dose at the age of 4-6 years. Immunisation coverage with MMR is high in children in Greece, but less than optimal in adolescents and young adults. In some population groups (e.g. Greek Roma) vaccination coverage is low. According to the last national study on vaccination coverage, carried out in 2006, about $99 \%$ of first grade school children (about 6 years-old) were immunised with one dose of a measles-containing vaccine, and $77 \%$ with two doses. In Roma children, coverage was $82 \%$ and $45 \%$ respectively, but this refers to Roma children going to school and may represent an overestimation of the coverage of all Roma children. In ninth grade school children (about 14 years-old), coverage with one dose of a measles-containing vaccine was $92 \%$, and $80 \%$ with two doses [12].

It is of concern that the age distribution of cases in the Greek Roma population (95\% of cases under 15 years) is similar to the one observed in many countries in the pre-vaccination era [13]. Children under the age of one year represented $8 \%$ of all cases (rate 9.1 per 100,000 population). In some recent outbreaks, the incidence of measles in this age group was found increased compared to previous years [14]. The hospitalisation rate we found $(66 \%)$ is similar to that reported in some recent outbreaks in Europe $[3,5]$ but higher than in others $[6,14]$, possibly reflecting a greater extent of underreporting of mild cases.

The occurrence of this outbreak highlights the need to achieve high vaccination coverage with two doses of MMR vaccine through routine immunisation in the general population (not only among children, but also among adolescents and young adults) and the need to increase immunisation coverage in hard-to-reach populations. It is equally important to have systematic policies that ensure good access to vaccination services for children in Roma communities in Greece.

\section{Acknowledgements}

We wish to sincerely thank clinicians and local public health authorities who contributed to measles surveillance in Greece.

\section{References}

1. EUVAC NET. Measles surveillance annual report 2009. Copenhagen: EUVAC NET. Available from: http://www.euvac. net/graphics/euvac/pdf/annual_2009.pdf

2. Lopalco PL, Martin R. Measles still spreads in Europe: who is responsible for the failure to vaccinate?. Euro Surveill. 2010;15(17): pii=19557. Available from: http://www. eurosurveillance.org/ViewArticle.aspx?Articleld=19557

3. Marinova L, Muscat M, Mihneva Z, Kojouharova M. An update on an ongoing measles outbreak in Bulgaria, AprilNovember 2009. Euro Surveill. 2009;14(50):pii=19442. Available from: http://www.eurosurveillance.org/ViewArticle. aspx?Articleld $=19442$

4. EUVAC NET. Measles outbreak in Bulgaria: update as of week 28, 2010. Copenhagen: EUVAC NET. Available from: http:// www.euvac.net/graphics/euvac/outbreak/bulgaria28.html

5. Orlikova H, Rogalska J, Kazanowska-Zielinska E, Jankowski T, Slodzinski J, Kess B, et al. Spotlight on measles 2010: A measles outbreak in a Roma population in Pulawy, eastern Poland, June to August 2009. Euro Surveill. 2010;15(17):pii=19550. Available from: http://www. eurosurveillance.org/ViewArticle. aspx?Articleld=19550

6. Gee S, Cotter S, O'Flanagan D, on behalf of the national incident management team. Spotlight on measles 2010: Measles outbreak in Ireland 2009-2010. Euro Surveill. 2010;15(9):pii=19500. Available from: http://www. eurosurveillance.org/ViewArticle.aspx?Articleld =19500

7. Bätzing-Feigenbaum J, Pruckner U, Beyer A, Sinn G, Dinter A, Mankertz A, et al. Spotlight on measles 2010: Preliminary report of an ongoing measles outbreak in a subpopulation with low vaccination coverage in Berlin, Germany, JanuaryMarch 2010. Euro Surveill. 2010;15(13):pii=19527. Available from: http://www.eurosurveillance.org/ViewArticle. aspx?Articleld $=19527$

8. Grgic-Vitek M, Frelih T, Ucakar V, Prosenc K, Tomažič J, Petrovec M, et al. Spotlight on measles 2010: A cluster of measles in a hospital setting in Slovenia, March 2010. Euro Surveill. 2010;15(20):pii=19573. Available from: http://www. eurosurveillance.org/ViewArticle.aspx?Articleld $=19573$

9. EUVAC NET. Measles outbreaks in Piemonte, Italy between 1 January 2010 and 13 May 2010. Copenhagen: EUVAC NET. Available from: http://www.euvac.net/graphics/euvac/ outbreak/italy5.html

10. European Commission. Commission Decision of 28 April 2008 amending Decision 2002/253/EC laying down case definitions for reporting communicable diseases to the Community network under Decision No 2119/98/EC of the European Parliament and of the Council. 18.06.2008:L 159. Available from: http://ec.europa.eu/health/ph_threats/com/ docs/1589_2008_en.pdf

11. Georgakopoulou T, Grylli C, Kalamara E, Katerelos P, Spala G, Panagiotopoulos T. Current measles outbreak in Greece. Euro 
Surveill. 2006;11(8):pii=2906. Available from: http://www. eurosurveillance.org/ViewArticle.aspx?Articleld=2906

12. Panagiotopoulos T, Georgakopoulou T, Stavrou D, Danis K, Laggas D, Georgiadou L, et al. Greek national study on vaccination coverage and occurrence of tuberculosis infection in children, 2006. Athens: National School of Public Health. 2009 [in Greek]. Available from: http://www.nsph.gr/files/o11 Ygeias_Paidiou/Ereunes/emvolia_tblimoxi_2006_ekthesi.pdf

13. Miller E, Nokes DJ, Anderson RM. Measles, mumps and rubella vaccination. BMJ. 1992;304(6839):1440-1.

14. Stein-Zamir C, Abramson N, Shoob H, Zentner G. An outbreak of measles in an ultra-orthodox Jewish community in Jerusalem, Israel, 2007 - an in-depth report. Euro

Surveill. 2008;13(8):pii=8045. Available from: http://www. eurosurveillance.org/ViewArticle.aspx?Articleld $=8045$ 